\title{
The influence of catalysts on the combustion of petroleum coke in the stationary fluidized bed mode
}

\author{
A A Sharipov ${ }^{1}, Y V$ Vankov $^{1, *}, K G$ Sadikov $^{2}$ and $E R$ Saifullin ${ }^{2}$ \\ ${ }^{1}$ Kazan State Power Engineering University, 51 Krasnoselskaya str., Kazan 420066, Russian Federation \\ ${ }^{2}$ Kazan Federal University, 18 Kremlyovskaya str., Kazan 420008, Russian Federation
}

\begin{abstract}
It is known that petroleum coke, a product of deep processing of oil, can be used as fuel in power boilers. The method of petroleum coke burning in a fluidized bed is the most optimal to complete its combustion. To improve the combustion characteristics of this fuel, we studied the influence of catalysts on the petroleum coke burning in the simulation mode of a stationary fluidized bed. The laboratory setup is described. The results of the experiments are given.
\end{abstract}

\section{Introduction}

The level of energy development of any country is determined not by the amount of extracted or consumed fuel and energy resources, but by the efficiency of their use. Today, many types of fuel are being researched, developed and used in the world, which are alternative to traditional types of fuel (gas, coal, fuel oil). In view of the development of energy production, one of the main tasks of any state is to search for new types of fuel that will fit technical and environmental standards [1-6]. Also, together with the solution of this problem, it is possible to solve other problems that exist in a particular industry [7-13]. One of these problems is a huge amount of petrochemical production wastes.

Problems of disposal of waste oil always remain relevant. One of the solutions to this problem is the production of petroleum coke. Further processing is impossible, and storage is not advisable. Therefore, worldwide, this product has found its application in metallurgy, in aluminum and cement productions, and in the energy sector [14].

In many developed countries, the experience of using petroleum coke as a fuel or a burnable additive makes an essential contribution to the global energy industry. In other countries, especially in the United States, approximately $30 \%$ of coke is burned in furnaces. Already in 2000, a combined-cycle gas turbine setup with gasification of petroleum coke with a gross capacity of $240 \mathrm{MW}$ was commissioned at the Delaware State Oil Refinery in the USA. In Latvia, MixOil, which is engaged in the development and preparation of fuels from petroleum waste, uses petroleum coke as the main fuel or as an additive to the main fuel. The Canadian producer of petroleum coke, located between the cities of Alberta and Saskatchewan, according to data for 2015, produced about 10 million tons of this product. Half of the coke produced was stored in warehouses and was not useful in any way. The manufacturer chose to import another part to other countries [15].

It is known that petroleum coke is most efficiently burned in the fluidized bed. Fluidized bed devices are widely used in industry due to the simplicity of the device, the intensity of action, ease of automation, the relatively small hydraulic resistance of the layer (regardless of the speed of the fluidizing agent).

The advantages of fluidized bed boilers are:

1. High efficiency. Fluidized bed boilers can burn fuel with a combustion efficiency of more than $95 \%$.

2. High heat transfer speed. This makes it possible to use boilers of small sizes.

3 . The ability to use different types of fuel.

4. The ability to burn low-grade fuel. Fluidized bed boilers give nominal capacity even during the lowquality fuels burning. Fuels containing as little as $1 \%$ carbon by weight can sustain fluidized bed combustion.

5. Easy operation. High layer turbulence facilitates quick start and shutdown. Full automation of start-up and operation using reliable equipment is possible [16].

Petroleum coke is a slow burning fuel. Therefore, there arises a problem of increasing the intensification of its combustion. There are known examples of the use of blast dust, coal ash and biofuel ash to intensify the petroleum coke burning. Presumably, some oxides contained in the petroleum coke ash can also serve as catalysts for the combustion process, affecting the melting temperature of the ash and its slagging. However, some of the oxides can serve as inhibitors. Taking into account the abovementioned, it was decided to study the impact of catalysts on the petroleum coke combustion in the mode of the so-called stationary fluidized bed [17]. 


\section{Description of the laboratory setup}

This study was conducted to determine the thermal effect of various types of solid fuels. It allows one to investigate the temperature change caused by the thermal impact in the process of petroleum coke burning during a dynamic air flow. It also gives the ability to assess the influence of catalysts on the combustion process [18].

The setup (Fig. 1) is a quartz cylindrical tube of 30 $\mathrm{cm}$ length. At the edges of the tube brass nuts are fastened with a small hole in the center for insertion a thermocouple into the setup. Quartz glass is poured into the tube to a height of $12-13 \mathrm{~cm}$. The glass is tamped with light strokes on the quartz tube. Then silica gel is filled up with a height of $2 \mathrm{~cm}$. The next step is to drop the sample, which is tamped with a small cylinder. The weight of the sample does not exceed 0.5 grams (height atmosphere). Due to this mixing, independent particles of petroleum coke are separated. A mixture of petroleum coke and silica gel is called the main sample.

A solvent, methylene chloride, was used to better mix some of the components. This solvent is quickly evaporated at room temperature. After mechanical mixing of dry substances, they are poured into the container. Further methylene chloride is poured in this container. The sample vessel is placed in the evaporation cabinet. After some time, the solvent evaporates and the mixture remains dry.

The main sample was obtained by mechanical mixing of $0.1 \mathrm{~g}$ petroleum coke and $0.4 \mathrm{~g}$ silica gel.

The second sample was obtained by mechanical mixing of $0.1 \mathrm{~g}$ of the main sample with the addition of $1 \%$ petroleum coke ash and $0.4 \mathrm{~g}$ of silica gel.

The third sample was obtained by mixing of $0.1 \mathrm{~g}$ of

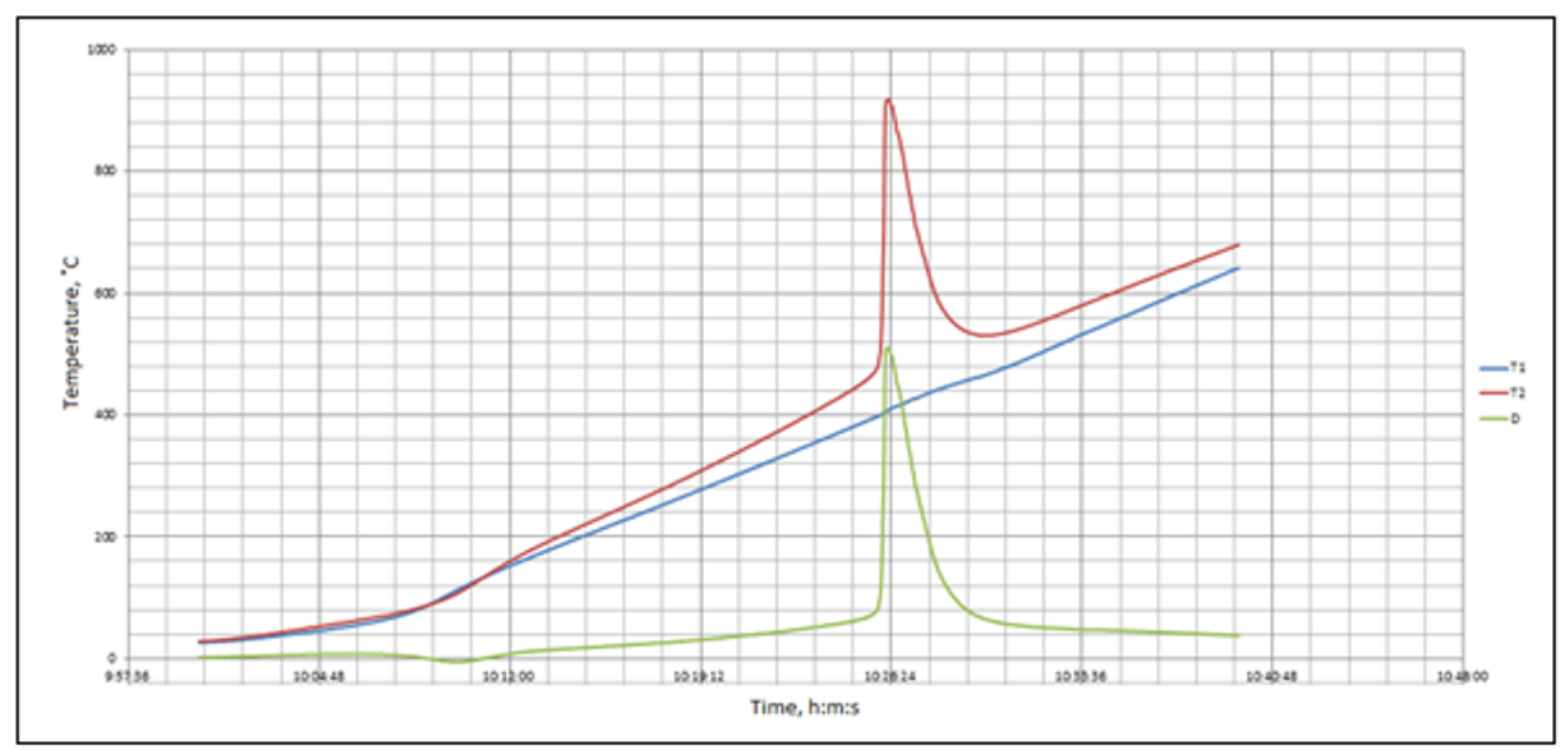

Fig. 2. The main sample burning.

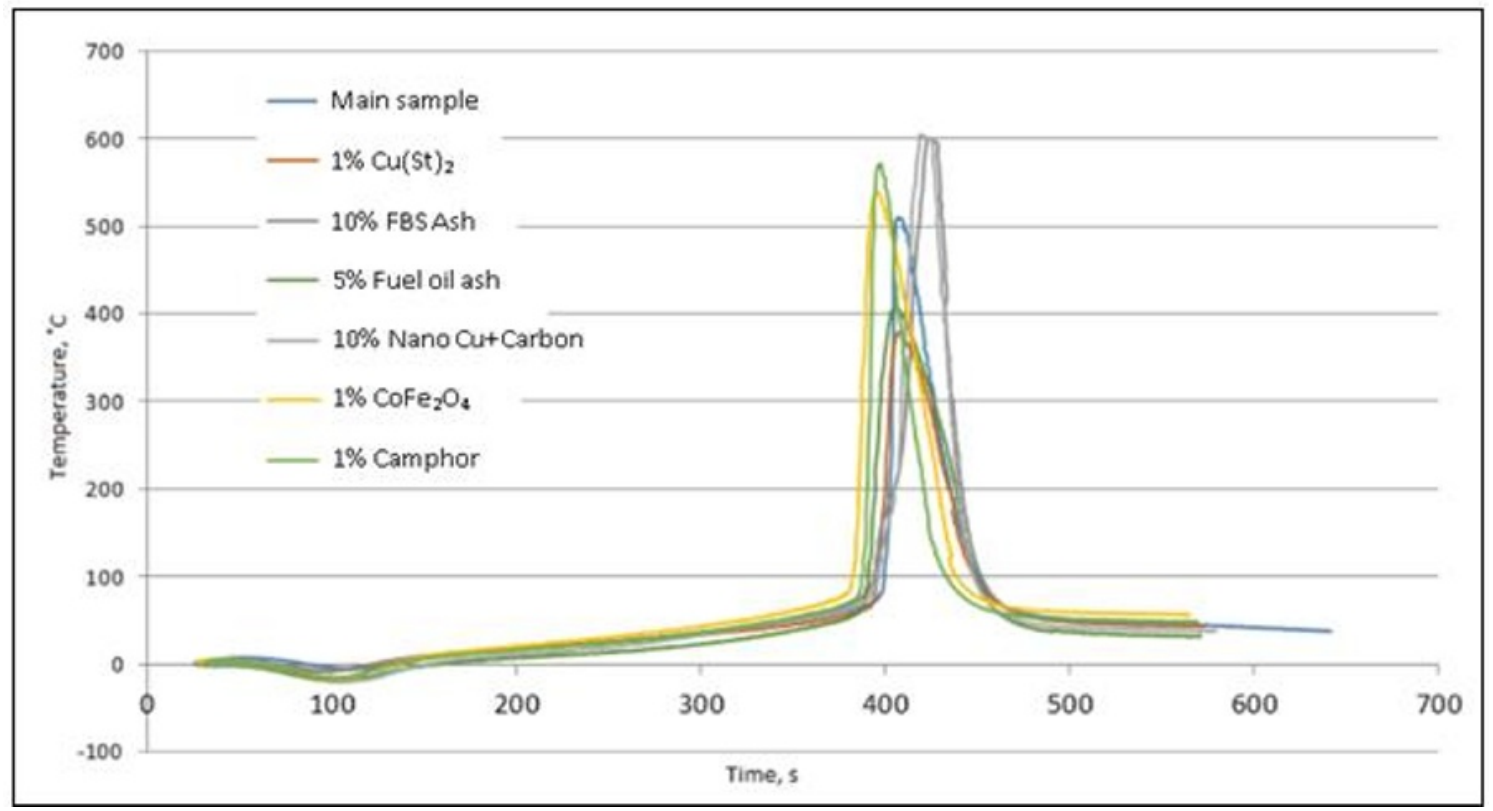

Fig. 3. Experimental results. 


\section{Results of the experiments}

The experiment of the main sample burning (petroleum coke with silica gel) is shown in fig. 2 .

Line T1 shows the temperature of petroleum coke. $\mathrm{T} 2$ shows the temperature of the silica gel that is in the heating zone from an external heat source. D is the temperature difference. This line shows the temperature change of the sample without taking into account the influence of the external heater.

The results of experiments with 7 different samples are shown in fig. 3. The graph shows the temperature difference for each sample.

We set the samples in ascending order according to the maximum temperature reached: $\mathrm{Cu}(\mathrm{St})_{2}$, fuel oil ash, mainsample, $\mathrm{CoFe}_{2} \mathrm{O}_{4}$, camphor, FBCash, NanoCu + Carbon. We conclude that $\mathrm{CoFe}_{2} \mathrm{O}_{4}$, camphor, FBCash, $\mathrm{NanoCu}+$ Carbon are catalysts. We also see that the growth speed of temperature in $\mathrm{CoFe}_{2} \mathrm{O}_{4}$, camphor, is noticeably higher than that of the other samples. In this regard, we can conclude that these substances increase the burning speed of petroleum coke.

\section{Conclusion}

According to the results of the experiments, it can be concluded that $\mathrm{CoFe}_{2} \mathrm{O}_{4}$, camphor, FBCash, NanoCu + Carbon, mixed with petroleum coke, are catalysts for its combustion. This is evident from their maximum burning temperature. It is also possible to note a more vertical angle of elevation of the $\mathrm{CoFe}_{2} \mathrm{O}_{4}$ curves, camphor, which means an increase in the burning speed. The simplest catalyst for petroleum coke is its own ash. Even after successful burning of coke, it is possible to improve the activation of its burning only with the help of its own ash. After the study, it becomes clear that the use of different types of catalyst increases the efficiency of petroleum coke burning. The use of catalysts to improve the petroleum coke combustion makes it possible to improve the technology of burning this product in modern and reconstructed power boilers. Today, only $30 \%$ of the total world stock of petroleum coke is used for combustion in power plants. When using the technology of adding catalysts to petroleum coke, it is possible to increase this index. The increase in this index makes it possible to rationally solve the disposal of a huge number of petrochemical residues, saving traditional fuel, and increasing the efficiency of fuel combustion. These factors, in turn, increase the indicators of world energy development.

\section{References}

1. N. Politaeva, Y. Smyatskaya, V. Slugin, A. Toumi, M. Bouabdelli, Effect of laser radiation on the cultivation rate of the microalga Chlorella sorokiniana as a source of biofuel, IOP Conference Series: Earth and Environmental Science, 115(1) (2018)

2. E. Shaburov, A. Fedyukhin, O. Derevianko, Analysis of Energy Efficiency of Municipal Solid Waste
Usage for Thermal and Electrical Energy Production, IOP Conference Series: Earth and Environmental Science, 272(2) (2019)

3. T. Kuznetsova, N. Politaeva, Y. Smyatskaya, A. Ivanova, Lemna Minor Cultivation for Biofuel Production, IOP Conference Series: Earth and Environmental Science, 272(2) (2019)

4. D.A. Cauich-López, L.F. Barrera Payan, A.M.N. Abdelhalim, E. Socolova, A.A. Sinitsyn, I.G. Akhmetova, Small-scale steam generation from local solid waste, International Journal of Civil Engineering and Technology, 10(2), 2118-2129 (2019)

5. T. Kuznetsova, N. Politaeva, Y. Smyatskaya, E.V. Trukhina, I. Atamanyuk, Energy Production from Chlorella Algae Biomass Under St. Petersburg Climatic Conditions, Chemical and Petroleum Engineering, 53(11-12), 801-805 (2018)

6. I.N. Borisov, O.S. Mandrikova, D.A. Mishin, Petroleum coke is an alternative fuel for a cement rotary furnace, Modern problems of science and education, 6 (2014)

7. N. Huang, P. Zhao, S. Ghosh, A. Fedyukhin, Cohydrothermal carbonization of polyvinyl chloride and moist biomass to remove chlorine and inorganics for clean fuel production, Applied Energy, 240, 882-892 (2019)

8. A. Fedyukhin, I. Sultanguzin, A. Gyul'Maliev, V. Sergeev, Biomass pyrolysis and gasification comprehensive modeling for effective power generation at combined cycle power plant, Eurasian Chemico-Technological Journal, 19(3), 245-253 (2017)

9. V.I. Sitas, A.V. Fedyukhin, I.G. Akhmetova, A. Mitrofanov, S.O. Makoev, A. Asadpoori, A.A. Sinitsyn, E.A. Kikot, Assessment of technical and economic efficiency indicators of cogeneration in modern market conditions, International Journal of Civil Engineering and Technology, 10(2), 21062117 (2019)

10. I. Sultanguzin, A. Fedyukhin, V. Karasevich, A. Chernykh, Implementation of compressed air energy storages (CAES) for increasing efficiency of natural gas usage for power generation, International Gas Research Conference Proceedings, 2, 1193-1198 (2017)

11. J. Saari, E. Sermyagina, J. Kaikko, E. Vakkilainen, V. Sergeev, Integration of hydrothermal carbonization and a CHP plant: Part 2 -operational and economic analysis, Energy, 113, 574585(2016)

12. G. Mingaleeva, D. Ermolaev, A. Galkeeva, Physicochemical foundations of produced syngas during gasification process of various hydrocarbon fuels, Clean Technologies and Environmental Policy, 18(1), 297-304 (2016)

13. E.R. Saifullin, Yu.V. Vankov, Optimization of burning process of hydrocarbon fuels with varying specific heat of combustion, IOP Conference Series: Materials Science and Engineering, 86(1) (2015)

14. P. Ganesh, M. Rajavel, P. Guruchandran, Comparison of combustion characteristics of 
Petcoke and Indian sub bituminous coal in a CFB Test facility, 7 INPRESSCO, 7(2) (2017)

15. D. Turnbull, J. Bendiksen, Petroleum coke: The coal hiding in the tap sands, OILCHANGE, 21 (2017)

16. J.S. Rueda, T. Pikkarainen, Asphaltene fluidized bed combustion, International flame research foundation (2018)

17. A. González, N. Moreno, Fly ashes from coal and petroleum coke combustion: Current and innovative potential applications, Waste Management \& Research, 27(10) (2017)

18. K. Sadikov, V. Larionov, M. Varfolomeev, Evaluation Method of Influence of Catalyst Precursors on Initiation of In-Situ Combustion and It's Dynamics, SPE Russian Petroleum Technology Conference (2017) 